\title{
Effects of Processing Methods on Mechanical Properties of Alkali Treated Bagasse Fibre Reinforced Epoxy Composite
}

\author{
Geoffrey Bem Nyior, Ekene Chukwuka Mgbeahuru \\ Department of Mechanical Engineering, University of Agriculture, Makurdi, Benue State, Nigeria \\ Email: appropriate2010@yahoo.com
}

How to cite this paper: Nyior, G.B. and Mgbeahuru, E.C. (2018) Effects of Processing Methods on Mechanical Properties of Alkali Treated Bagasse Fibre Reinforced Epoxy Composite. Journal of Minerals and Materials Characterization and Engineering, 6, 345-355.

https://doi.org/10.4236/jmmce.2018.63024

Received: February 22, 2018

Accepted: May 8, 2018

Published: May 11, 2018

Copyright $\odot 2018$ by authors and Scientific Research Publishing Inc. This work is licensed under the Creative Commons Attribution International License (CC BY 4.0).

http://creativecommons.org/licenses/by/4.0/

\begin{abstract}
Effects of the processing methods on the mechanical properties of treated bagasse fibre reinforced epoxy composite were evaluated. The composite materials were processed by employing hand lay-up and compression moulding methods and fibres were treated with $\mathrm{NaOH}$ solution. The composite samples were subjected to tensile, flexural and impact tests. Based on the findings, compression moulding method produced better mechanical properties compared to the composites manufactured by hand lay-up method. The results showed that the tensile strength and Young's modulus of the samples produced by compression moulding method increased by 77 percent and 47 percent respectively (at optimal fibre loading) compared to those produced by the hand lay-up method. The results also showed noticeable improvements in the impact strength of the material produced by compression moulding method, with impact strength of $11.5 \mathrm{~kJ} / \mathrm{m}^{2}$ against the samples produced by hand lay-up method, with impact strength of $7 \mathrm{~kJ} / \mathrm{m}^{2}$.
\end{abstract}

\section{Keywords}

Hand Lay-Up Method, Compression Moulding Method, Alkali, Bagasse Fibre and Epoxy

\section{Introduction}

In recent years, natural fibres have been the most widely used fibre in the composite industry. This is because natural fibres have many exceptional properties that are difficult or impossible to match with synthetic fibres. These advantages include renewable, environment friendly, low cost, low density, flexibility of usage and biodegradability [1]. 
Studies on the use of natural fibres such as bagasse, as replacement to synthetic fibre in fibre-reinforced composites have increased and opened up further industrial possibilities. Natural fibre-reinforced composites can be applied in the plastics, automobile and packaging industries at minimal material cost [2]. The processing of natural fibre composites and the final product properties are influenced significantly by factors such as moisture content of fibre, fibre loading etc. The fabrication method of a natural fibre composite material influences the mechanical properties and is strongly related to parameters such as the length of fibre and the resin used [3]. Therefore, selection of the appropriate fabrication process for natural fibre reinforced composites is very important. The fabrication of natural fibre reinforced polymer composites is a multifaceted process that includes steps such as preparation, distribution on fibres on matrix, and curing [4]. The efforts to produce economically attractive composite components have resulted in several innovative manufacturing techniques currently being used in the composites industry. Increasingly enabled by the introduction of newer polymer resin matrix materials and reinforcement fibres, the penetration of these advanced materials has witnessed a steady expansion in uses and volume [5].

[6] investigated the effects of production methods and material ratios on the physical and mechanical properties of recycled plastic/bamboo fibres reinforced composites. Two processing methods were employed namely; compression moulding and open casting methods. Results show that the compression moulded composites gave better physical and mechanical properties than the open casting method, possibly due to reduced void space during polymerisation. The study therefore suggested that reducing void space and incorporating fibres into plastics improve the end use properties. [7] studied the effect of fabrication processes and material combinations on the mechanical properties of fibre reinforced polymer composites. The mechanical properties of carbon and glass fibre reinforced polymer matrix composites were investigated by altering the fabrication method. The processes used for composite fabrication were hand lay-up, vacuum bag moulding and vacuum assisted resin infusion. The resin systems used included polyester, vinyl ester and epoxy. Results showed that optimum mechanical properties were achieved using vacuum assisted resin infusion method in the carbon reinforced polyester and epoxy based composites. [8] investigated the effects of processing methods, moisture content and resin system on physical and mechanical properties of woven kenaf plant fibre composites. The resins used were epoxy, unsaturated polyester (UP) and vinyl ester fabricated using hand lay-up with cold press (HCP) and vacuum infusion (VI). The results of the samples produced by hand lay-up with cold press showed a noticeable improvement in tensile and flexural strength and their moduli for all types of polymer used compared with the samples produced by vacuum infusion in ascending order from unsaturated polyester, vinyl ester to epoxy. [9] studied 50 percent wood-flour filled high density polyethylene (HDPE) composites manufactured by extrusion, compression moulding and injection moulding 
methods. The extruded composites absorbed the most moisture and injection moulding composites absorbed the least moisture. The results were attributed to a polymer-rich surface layer and lower void content attributable to the higher density of injection moulded composites. [10] investigated the mechanical properties of kenaf fibre reinforced polyester composites fabricated with vacuum infusion and hand lay-up methods. The kenaf fibre was treated with two concentrations of $\mathrm{NaOH}$. The results showed that the composites produced by vacuum infusion process appear to have a slight improvement in the tensile properties compared with composites manufactured by the hand lay-up method.

Consequently, in this study, comparison was made between mechanical properties of treated bagasse fibre reinforced epoxy composite materials produced by two different methods namely compression moulding and hand lay-up methods.

\section{Materials and Methods}

\section{Materials and Equipment}

The materials used in the production of the specimens include; Epoxy matrix, bagasse fibre, Sodium Hydroxide, hardener, release agent \& catalyst.

The equipment includes; mould, compression moulding machine, electronic digital weighing scale, universal testing machine, flexural testing machine and impact testing machine.

\section{Bagasse Fibre Preparation}

Fresh bagasse fibres were collected, spread on a water proof sheet and sun-dried to remove or reduce the moisture content. After approximately two weeks, the long bagasse fibres were shortened to a length of $20 \mathrm{~mm}$, with a pair of scissors. These fibres were selected in order to design a composite with consistent properties. The bagasse fibres were then washed with water. This procedure removed fine bagasse particles, sugar residues and organic materials from the fibres. The fibres were then sundried and kept in an enclosed container to avoid absorbing moisture.

\section{Fibre Treatment}

The bagasse fibres were sorted out, cleaned and dipped in $10 \%$ solution of $\mathrm{NaOH}$ for 1 hour at room temperature. After this process, the fibres were thoroughly washed with distilled water. Thereafter, the $\mathrm{NaOH}$ treated fibres were dried for twenty four hours.

\section{Composite Preparation}

The composites were prepared using these two methods.

\section{Hand Lay-Up Method.}

A mould of dimension $(300 \times 100 \times 5) \mathrm{mm}$ was used for casting the composite sheet. The samples were manufactured with $5 \%, 10 \%, 15 \%$, and $20 \%$ volume fraction of treated bagasse fibres. For different volume fraction of fibres, a calculated amount of epoxy resin and hardener (ratio of 10:1 by weight) was thoroughly mixed with gentle stirring to minimize air entrapment. For quick and easy removal of composite sheets, a mould release spray was applied at the inner 
surface of the mould. Some amount of fibres was then distributed manually on the mould and the thoroughly mixed resin was poured into the mould. Care was taken to avoid formation of air bubbles. Subsequent layers of the fibres were then added. A roller was used to thoroughly wet the fibres and remove air entrapment. The sample was left at room temperature to cure. After some days the samples were taken out of the mould and kept for further investigations.

\section{Compression Moulding Method}

In this method, two matched metal moulds are used to produce the composite. The lower mould is stationary while upper mould is movable. A calculated amount of epoxy resin and hardener (ratio of 10:1 by weight) was thoroughly mixed with gentle stirring to minimize air entrapment. Some amount of fibres was then distributed on the lower mould and the thoroughly mixed resin was poured into the mould and the remaining fibres distributed carefully to consolidate the laminate thickness. The whole assembly was kept in between the compression moulder. After several trials at different pressures, pressure of $500 \mathrm{MPa}$ was selected and applied for a period of some hours on the mould using the hydraulic press. Beyond this pressure the mould was disfigured. The material placed in between the moulding plates flow due to application of pressure and acquires the shape of the mould cavity with high dimensional accuracy which depends upon mould design. Curing of the composite was carried out at room temperature. After curing, the mould was opened and composite product removed for further investigations. This procedure was adopted for preparation of $5 \%, 10 \%, 15 \%$, and $20 \%$ volume fractions of composites for the treated bagasse fibres.

\section{Mechanical Testing}

\section{Tensile test}

The tensile test of the composites was carried out with Monsanto Tensometer Type " $W$ " in accordance with the ASTM D638 procedure. The dimension of the sample was $100 \mathrm{~mm} \times 10 \mathrm{~mm} \times 5 \mathrm{~mm}$, with a gauge length was $40 \mathrm{~mm}$. The test was conducted by gripping each end of a reduced section specimen and slowly pulling it until catastrophic failure occurs.

\section{Flexural test}

The flexural test was performed using a $100 \mathrm{kN}$ capacity Universal Materials Testing Machine. It was conducted in accordance with ASTM D790 using the 3-point bending fixture utilizing centre loading on a simple supported beam. A bar of rectangular cross section rests on two supports and is loaded by means of a loading nose midway between the supports. The dimension of the sample was $100 \mathrm{~mm} \times 30 \mathrm{~mm} \times 5 \mathrm{~mm}$.

\section{Impact test}

The impact test was done using the Charpy Impact Testing Machine with $15 \mathrm{~J}$ capacity in according to ASTM standard D-256. In this method, the specimen was supported horizontally as a simple beam and fractured by a blow delivered in the middle by the pendulum. The sample size was $80 \mathrm{~mm} \times 10 \mathrm{~mm} \times 5 \mathrm{~mm}$. 


\section{Results and Discussion}

\section{Tensile Test}

Figure 1 shows the results of the tensile strength for the various specimens.

It was noticed from all tested materials as shown above, that the hand lay-up method gave a maximum tensile strength of $3.66 \mathrm{MPa}$ at 20 percent reinforcement while the compression moulding method gave a better result with a maximum tensile strength of $16.23 \mathrm{MPa}$ at 20 percent reinforcement.

It is clear that tensile strength increases as the percentage reinforcement increases. The tensile strength increased by 21 percent for samples produced by hand lay-up method, while the tensile strength for samples produced by compression moulding method increased by 64 percent. Results show that compression moulding method gave better results than the hand lay-up method. This was attributed to the fact that the compression moulding method ensures a uniform resin distribution over the fibres leading to less void contents than the hand lay-up method. The presence of voids might be a contributing factor for the drop in tensile strength [11].

Figure 2 shows the results of the percentage elongation for the various specimens.

It was observed that the percentage (\%) elongation increases as the fibre volume increases. This is in agreement with [12], who found out that the percentage elongation of material increased with increasing fibre percentage. This is contrary to the findings of [13] whose work revealed that $\%$ elongation at break of the composite samples investigated decreased with increase in filler loading. This is because the presence of filler imparts the stiffening effect within the matrix and thus imposed a mechanical restraint on the composite. The samples

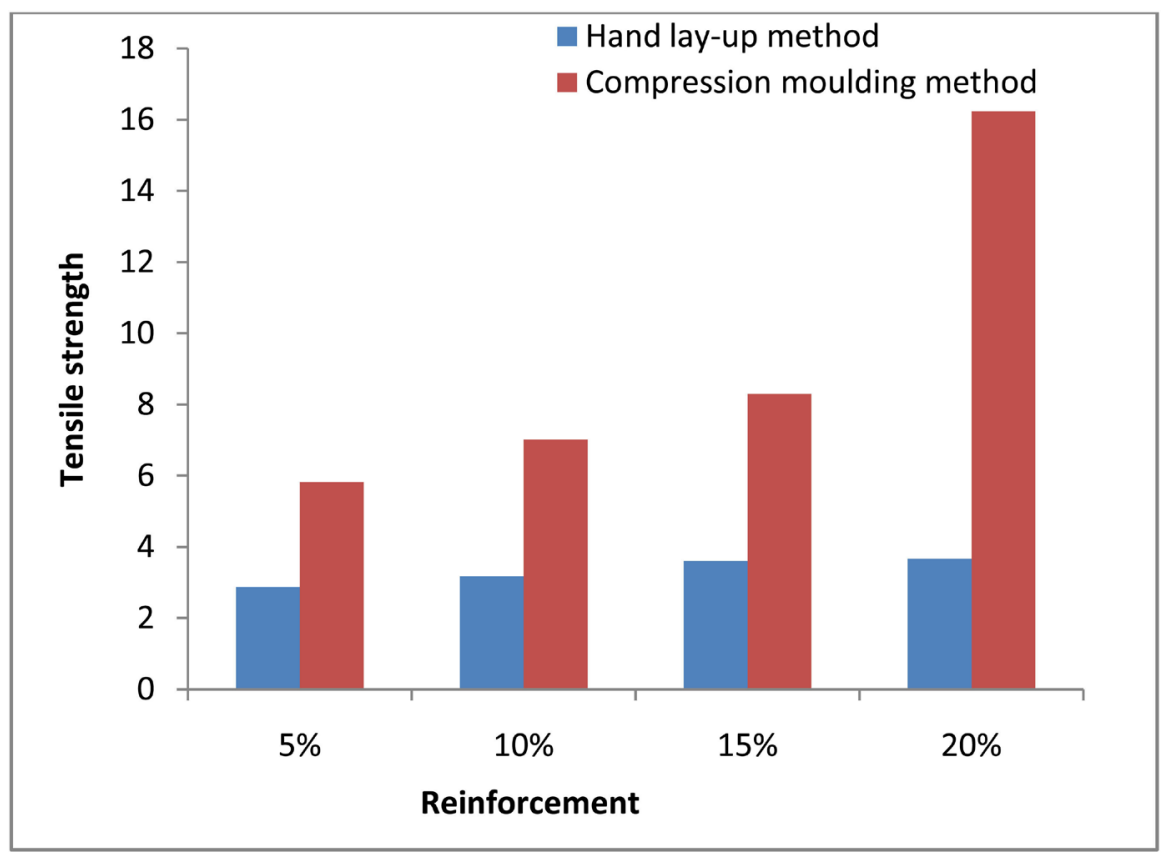

Figure 1. Tensile strength against reinforcement for various fibre loadings. 
produced by hand lay-up method showed less elongation than their compression moulding method counterparts, this could be attributed to high bonding between fibre and matrix in the compression moulded samples as the resin has low elongation at break [14].

Figure 3 shows the results of the Young's modulus for the various specimens.

The results gave a maximum value of $55.25 \mathrm{MPa}$ at 20 percent reinforcement for samples of the hand lay-up method and $105.56 \mathrm{MPa}$ at 20 percent reinforcement

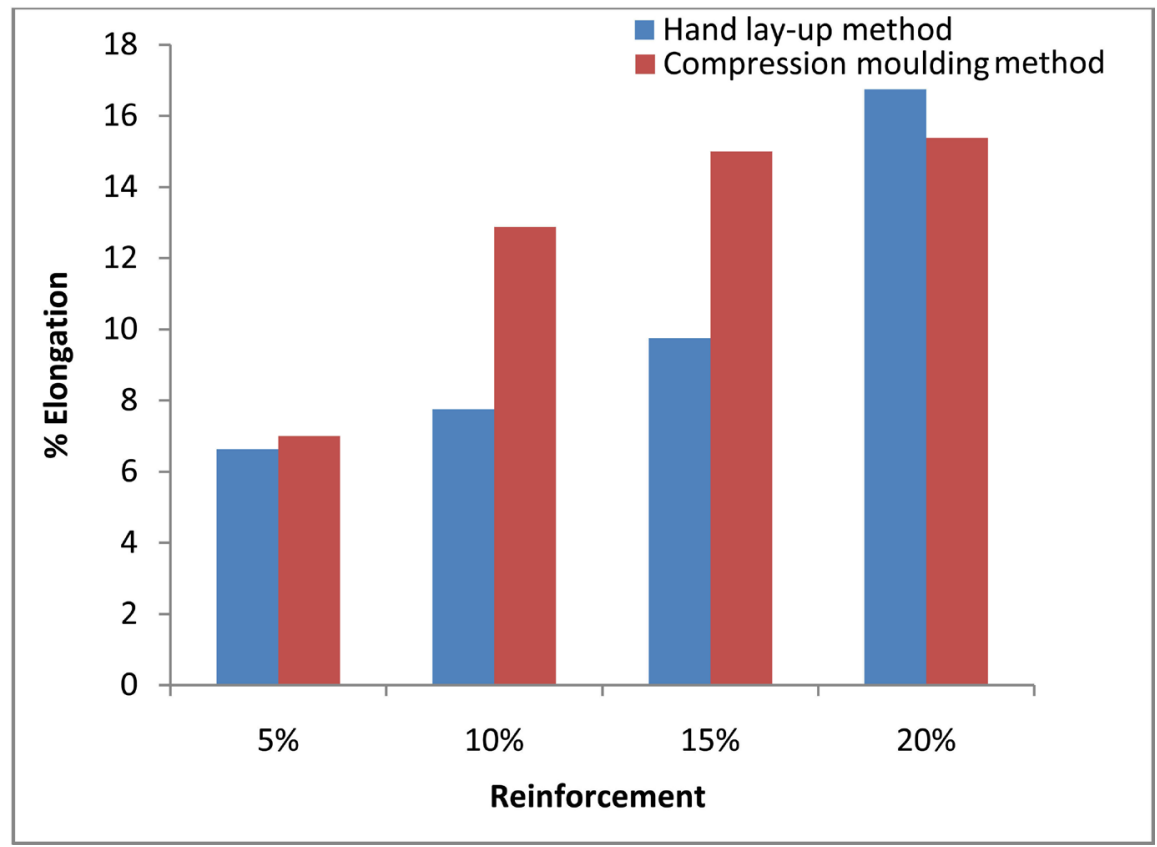

Figure 2. \% Elongation against reinforcement for various fibre loadings.

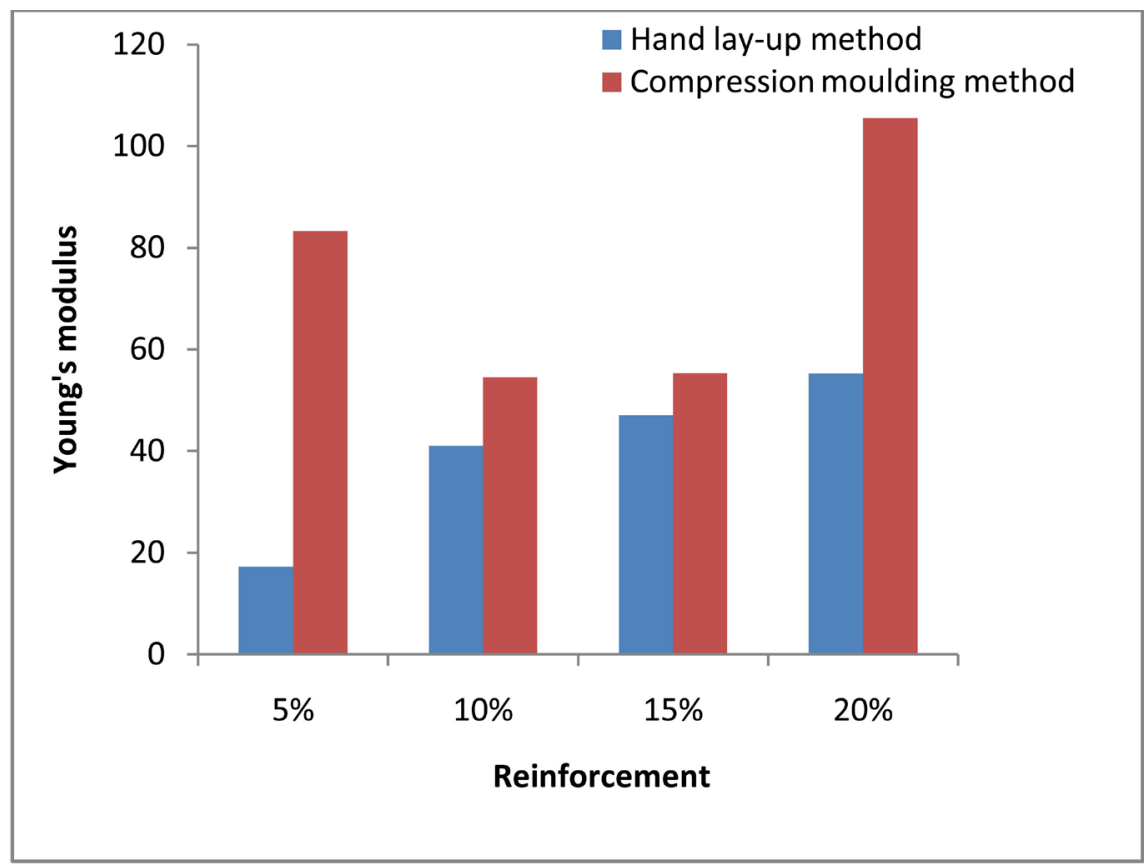

Figure 3. Young's modulus against reinforcement for various fibre loadings. 
for samples produced by compression moulding method. The Young's modulus results show that compression moulding method gave better results than hand lay-up method. This is likely due to the level of pressure applied to the samples by the compression moulding method which made them denser, and also the adhesion between the fibres and the epoxy is far better in compression moulding method than the adhesion in hand lay-up method.

The Young's modulus increases as the fibre volume increases. It was observed by many researchers that the Young's modulus increases with an increase in fibre loading [15] \& [16]. This behaviour may possibly lead to the conclusion that tensile moduli perhaps depend on the fibre content rather than particle-matrix interface [17].

\section{Flexural test}

The results of the flexural tests for the investigated materials are shown in Figure 4 and Figure 5.

From Figure 4, the modulus of elasticity showed a maximum of $393.47 \mathrm{MPa}$ at 15 percent reinforcement for hand lay-up method and $1567.04 \mathrm{MPa}$ at 15 percent reinforcement for compression moulding method. It was observed that the modulus of elasticity increases as the fibre weight content increases, up to a threshold point of 15 percent weight before experiencing depreciation. This is likely to happen because as the fibre content increases, the tendency for the fibre/matrix bonding strength decreasing is high. At low fibre content, the bagasse fibres were wetted properly by the epoxy and there is little or no contact among the fibres. Enhancement of mechanical properties was possible due to adequate wetting and bonding between the sugarcane fibre and the epoxy. This

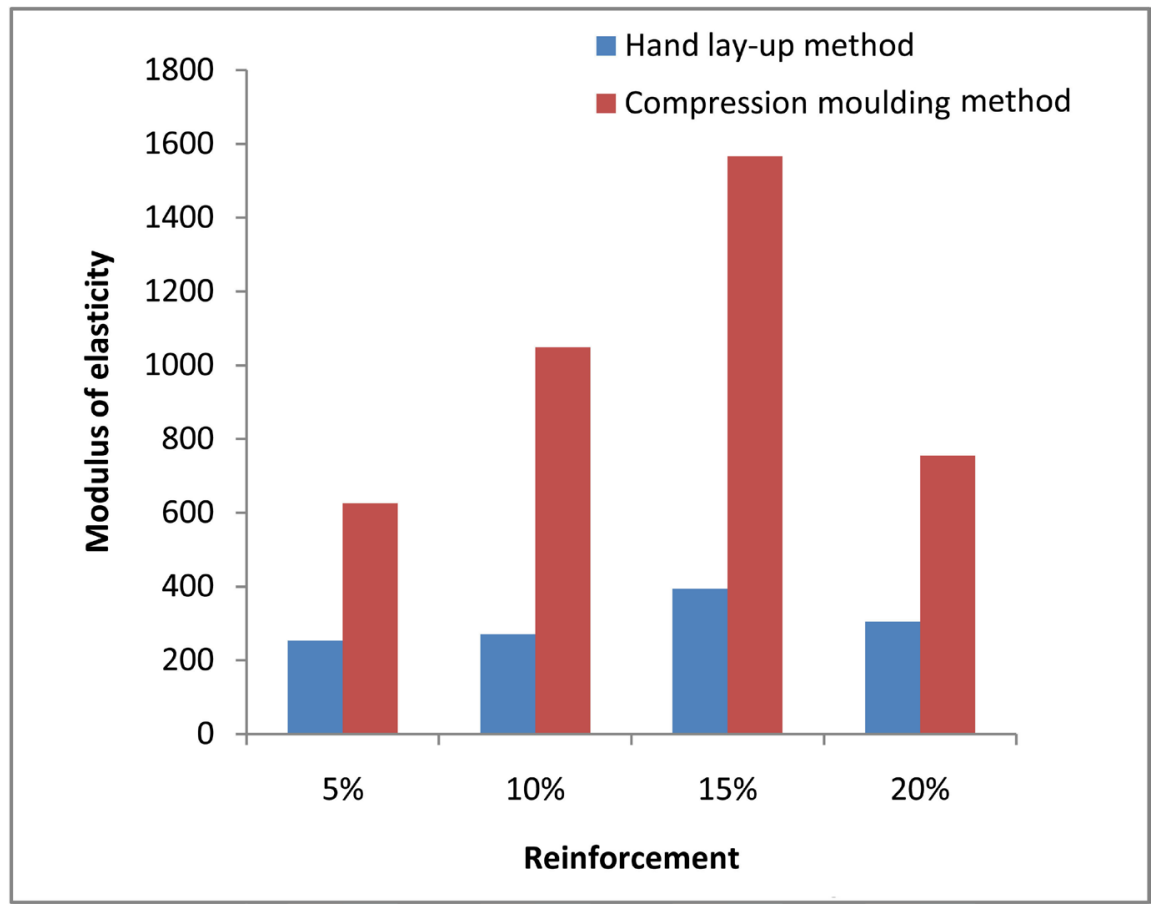

Figure 4. Modulus of elasticity against reinforcement for various fibre loadings. 


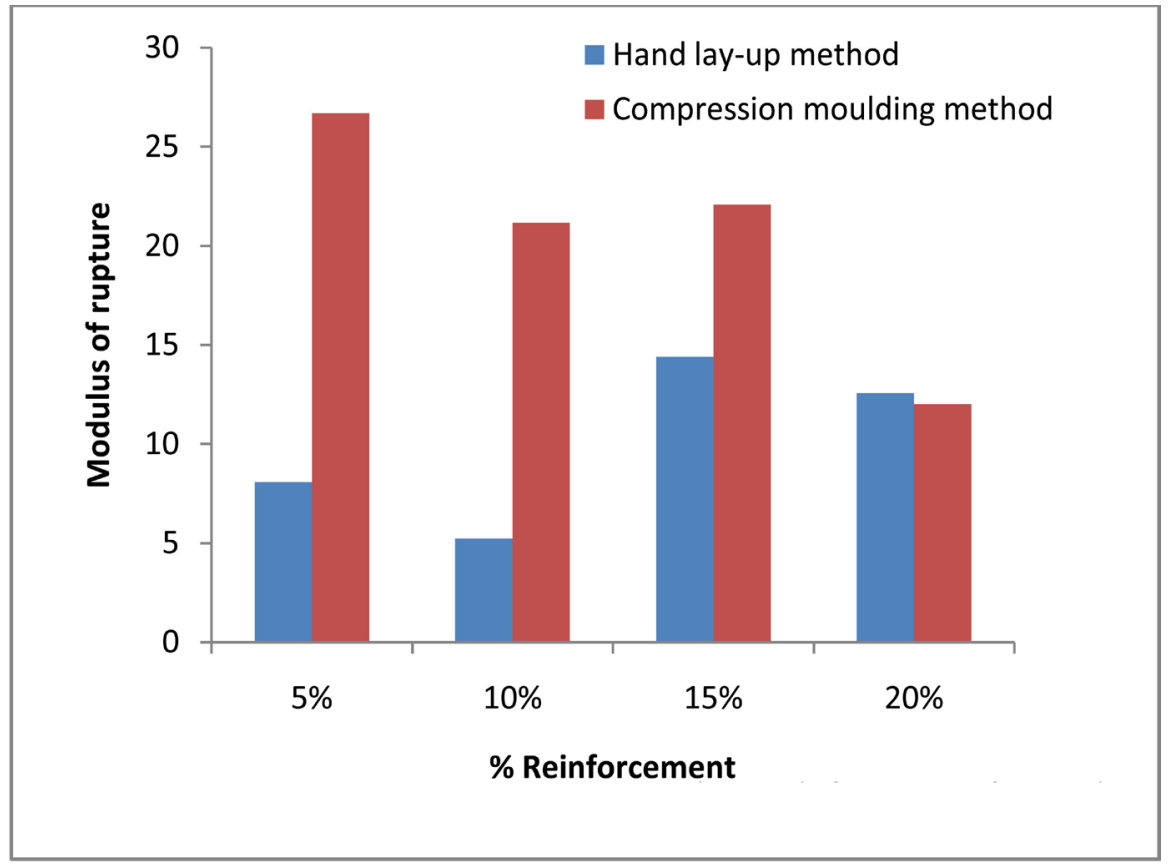

Figure 5. Modulus of rupture against reinforcement for various fibre loadings.

is in agreement with the work of [18]. The poor properties at higher loading may be due to insufficient wetting of fibres by resin for higher fibre content.

From Figure 5, the modulus of rupture for samples produced by hand lay-up method showed a maximum of $14.41 \mathrm{MPa}$ at 15 percent reinforcement and 26.69 $\mathrm{MPa}$ at 5 percent reinforcement for compression moulding method.

The results showed that the samples produced by compression moulding method gave better results than the hand lay-up method. This could be due to better fibre-matrix adhesion experienced in the compression moulding method due to high pressure applied on the material.

\section{Impact Strength}

Results of the impact strength for the various specimens are shown in Figure 6.

From the graph of impact strength plotted against reinforcement, it was observed that compression moulding method gave higher values of impact strength than the hand lay-up method. The result showed maximum impact strength of 7 $\mathrm{kJ} / \mathrm{m}^{2}$ at 15 percent reinforcement for the hand lay-up method and $11.5 \mathrm{~kJ} / \mathrm{m}^{2}$ at 15 percent reinforcement for the compression moulding method. This shows that the impact strength increased as the reinforcement increased up to 15 percent reinforcement before experiencing depreciation. This could be attributed to the fact that as the fibre content increased beyond 15 percent reinforcement, the fibre/matrix bonding strength weakened. At low fibre content, the bagasse fibres were wetted properly by the epoxy and there is little or no contact among the fibres. It is essential to find out the optimum fibre loading to achieve optimal properties [19]. The result is in agreement with [20] who observed that the impact strength increases with the increase in fibre content up to 15 percentage 


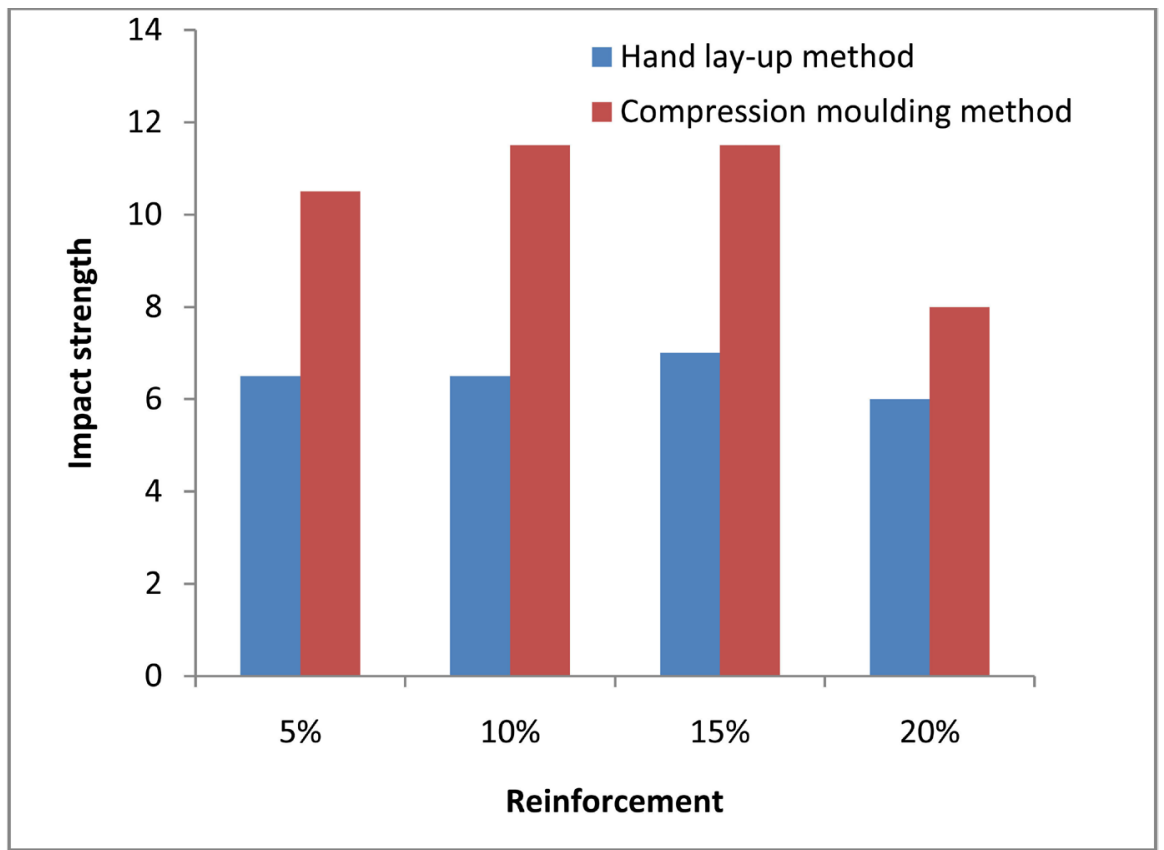

Figure 6. Impact strength against reinforcement for various fibre loadings.

weight and then decreases at higher loads. It has been reported that high fibre content increases the probability of fibre agglomeration with attendant stress concentration, requiring less energy for crack propagation. The impact strength of all composites increased with fibre content up to 15 percentage weight. Similar behaviour of composite materials was also observed by [15] and [21], that, impact strength decreases for higher filler loading beyond 50 percent reinforcement.

Samples produced by the compression moulding method gave better results with maximum impact strength of $11.5 \mathrm{~kJ} / \mathrm{m}^{2}$ than the samples produced by the hand lay-up method with maximum impact strength of $7 \mathrm{~kJ} / \mathrm{m}^{2}$. The reason could be that the fibres in compression moulding method absorbed compressive pressure which removed void contents in the composites, thereby leading to appreciative fibre/matrix mix up.

\section{Conclusions}

The bagasse fibre reinforced composite samples were fabricated and tested. The composite samples were subjected to mechanical testing namely tensile, flexural and impact tests. Based on the results of the tests, and the discussions therefrom, the following conclusions were drawn;

- Compression moulding method of fabricating composites gave better mechanical properties for the tested samples than the traditional hand lay-up method. The tensile strength and Young's modulus of the compression moulding method increased by 77 percent and 47 percent respectively compared to the hand lay-up method. And the properties increased as the percentage reinforcement increased. 
- The modulus of elasticity for the compression moulding method was higher than the hand lay-up method, with optimum value at 15 percent weight reinforcement.

\section{References}

[1] Yousif, B.F., Wong, K.J. and El-Tayeb, N.S.M. (2007) An Investigated on Tensile, Compression and Flexural Properties of Natural Fibre Reinforced Polyester Composites. ASME International Mechanical Engineering Congress and Exposition, Washington DC.

[2] Ajith, G., Senthil Kumar, M. and Elayaperumal, A. (2014) Experimental Investigations on Mechanical Properties of Jute Fiber Reinforced Composites with Polyester and Epoxy Resin Matrices. Procedia Engineering, 97, 2052-2063.

https://doi.org/10.1016/j.proeng.2014.12.448

[3] Thakur, V.K. and Thakur, M.K. (2014) Processing and Characterization of Natural Cellulose/Thermo-Set Polymer Composites. Carbohydrate Polymers, 109, 102-117. https://doi.org/10.1016/j.carbpol.2014.03.039

[4] Salit, M.S. (2015) Manufacturing Process of Natural Fibre Reinforced Polymer Composites. Springer International Publishing, Switzerland.

[5] Mehar, S.K. (2009) Weathering Behaviour of Bagasse Fibre Reinforced Polymer Composite. Thesis, National Institute of Technology, Rourkela.

[6] Matoke G.M., Owido S.F. and Nyaanga D.M. (2012) Effects of Production Methods and Material Ratios on Physical and Mechanical Properties of the Composites. American International Journal of Contemporary Research, 2, 208.

[7] Ertan, R. (2016) The Effect of Fabrication Processes and Material Combinations on the Mechanical Properties of Fibre Reinforced Polymer Composites. Proceedings of the IRES International Conference, Barcelona, 19 June 2016, 1-4.

[8] Mohaiman, S.J., Salman, S.D., Leman, Z., Sultan, M.T.H., Ishak, M.R. and Azmah Hanim, M.A. (2016) Effects of Processing Method, Moisture Content and Resin System on Physical and Mechanical Properties of Woven Kenaf Plant Fibre Composites. BioResources, 11, 1466-1476.

[9] Clemons, C.M. and Ibach, R.E. (2004) Effects of Processing Methods and Moisture History on Laboratory Fungal Resistance of Wood HDPE Composite. Forest Products Journal, 54, 50.

[10] Yuhazri, Y.M., Phongsakorn, P.T. and Sihombing H. (2010) A Comparison Process between Vacuum Infusion and Hand Lay-Up Method toward Kenaf/Polyester Composite. International Journal of Basic \& Applied Sciences, 10, 63-66.

[11] Rashdi, A.A.A., Sapuan, S.M., Ahmad, M.M.H.M. and Khalina, A. (2010) Combined Effect of Water Absorption Due to Water Immersion, Soil Burial and Natural Weather on Mechanical Properties of Kenaf Fibre Unsaturated Polyester Composites (KFUPC). International Journal of Mechanical and Materials Engineering, 5, 11-17.

[12] Maneesh, T., Singh, V.K., Gope, P.C. and Chaudhary Arun, K. (2011) Evaluation of Mechanical Properties of Bagasse Glass Fibre Reinforced Composite.

[13] Nwanonenyi, S.C. and Anyanwu, P.I. (2013) Studies on the Properties of Pine-Apple Leaves Powder Filled Low Density Polyethylene. Part II, Natural and Applied Sciences, 4, 359-367.

[14] Ratna Prasad, A. and Mohana Rao, K. (2011) Mechanical Properties of Natural Fibre Reinforced Polyester Composites: Jowar, Sisal and Bamboo. Materials and De- 
sign, 32, 4658-4663. https://doi.org/10.1016/j.matdes.2011.03.015

[15] Haque, M.M., Hassan, M., Islam, M.S. and Ali, M.E. (2009) Physico-Mechanical Propertiesof Chemically Treated Palm and Coir Fibre Reinforced Polypropylene Composites. Bioresource Technology, 100, 4903-4906.

[16] Bhaduri, S.K.P. (2008) Mojumdar. Natural Product Radiance, 2, 106.

[17] Raju, G.U., Kumarappa, S. and Gaitonde, V.N. (2012) Mechanical and Physical Characterisation of Agricultural Waste Reinforced Polymer Composite. Journal of Materials and Environmental Science, 3, 907-916.

[18] El-Tayeb, N.S.M. (2008) Abrasive Wear Performance of Untreated SCF Reinforced Polymer Composite. Journal of Material Processing Technology, 206, 305-314.

[19] Shibata, M., Takachiyo, K.-I., Ozawa, K., Yosomiya, R. and Takeishi, H. (2002) Biodegradable Polyester Composites Reinforced with Short Abaca Fibre. Journal of Applied Polymer Science, 85, 129-138.

[20] Geetanjali, D. and Sandhayarani, B. (2016) Physical, Mechanical and Water Absorption Behaviour of Coir Fiber Reinforced Epoxy Composites Filled with $\mathrm{Al}_{2} \mathrm{O}_{3}$ Particulates.

[21] Joseph, S., Sreekala, M.S., Oommen, Z., Koshy, P. and Thomas, S. (2002) A Comparison of the Mechanical Properties of Phenol Formaldehyde Composites Reinforced with Banana Fibres and Glass Fibres. Composites Science and Technology, 62, 1857-1868. 